\title{
Por uma nova agenda de investigação da história da TV no Brasil \\ João Freire Filho*
}

\section{RESUMO}

Na primeira parte deste artigo, apresento um panorama internacional da emergência da história da televisão como objeto de estudo acadêmico. Examino, em seguida, embaraços teóricos e metodológicos enfrentados pelo historiador do meio, ressaltando, ainda, os principais dominios de investigação explorados a partir dos anos 90. Na conclusāo, discuto os pro. pósitos e as práticas das (escassas) histórias da TV brasileira, refletindo sobre minhas próprias incursōes no campo.

\section{ABSTRACT}

In the first section of this article, I present an international oveniew of the emergence of television history as an object of academic study. Then, I exam then the theorical and methodological embarrassments faced by the research. I also emphasize the principal domains of investigation explored since the 1990's. In the conclusion I discuss the purposes and practices of Brazilian television historiographies and I reflect on my own incursions into the field. 
As estratégias retóricas e discursivas da TV são indiciadas, amiúde, como principais responsáveis pela degeneração do senso histórico e da memória individual e coletiva - marca registrada da vida pós-moderna. Não seria descabido incluir os críticos da televisão entre as vítimas mais notáveis da alegada perda do juízo histórico promovida pela corrosão catódica. Análises e teorias sobre o meio e seu aparato tendem a cingir-se ao atual, ao contemporâneo - uma opção epistemológica que traz o risco de essencializar a televisão num "presente perpétuo", que desvia a atenção dos processos de mudança nos quais a gramática dos significados e das representações é formada, e por meio dos quais convenções de linguagem, técnicas e "práticas significantes" específicas se tornam institucionalizadas (Caughie 2000: 14; Corner 1999: 121).

Por motivos que esmiuçarei mais adiante, a academia começa, felizmente, a despertar para ausências e fragilidades elementares no conhecimento existente sobre a televisão, buscando compreensão mais sólida de seu passado e de seu desenvolvimento social e cultural. Outrora quase um monopólio de antigos profissionais do ramo e de entusiastas de determinados gêneros ou programas, a história da TV se tornou, a partir dos anos 90 , objeto de sucessivas abordagens científicas - em especial, nos Estados Unidos e na Inglaterra (países onde o serviço televisivo se consolidou precocemente), mas também na Alemanha, Austrália, Espanha, Canadá, França, Itália e Escandinávia (dentro do contexto da desregulamentação, digitalização e convergência do sistema midiático).

$\mathrm{Na}$ primeira parte deste artigo, apresento um breve panorama internacional desta emergência da história da televisão como objeto de estudo acadêmico. Examino, em seguida, embaraços teóricos e metodológicos enfrentados pelo historiador do meio, destacando, ainda, as linhas de investigação mais promissoras. Na conclusão, discuto propósitos e práticas das histórias da TV brasileira, refletindo acerca de minhas próprias incursões no campo. Argumento que a pesquisa histórica teórica e metodologicamente bem fundamentada favorece, entre outras contribuições, a clarificação ou reformulação de pressupostos e conceitos teóricos sobre as características tecnológicas e a organização social e textual do meio que se naturalizaram com o tempo, bloqueando a reflexão e o discurso crítico.

\section{A "virada histórica" nos estudos televisivos}

As comemorações do cinquientenário da TV, em vários cantos do globo, de meados da década de $1980 \mathrm{em}$ diante, contribuíram, sem dúvida, para aguçar a percepção da historicidade do meio e, por tabela, para incrementar a sondagem histórica. $O$ aniversário natalício não se constitui, todavia, na única e nem na mais importante justificativa para que a história da televisão deixe de ser uma rara avis bibliográfica. Deve-se, antes mais nada, situar a 
curiosidade cientifica sobre a história da televisão dentro do quadro mais amplo de renovado interesse internacional pela história da mídia como um todo, tanto por parte dos historiadores como de pesquisadores das áreas cognatas da comunicação e dos estudos culturais (Bondebjerg 2002; Briggs \& Burke 2002; Brügger \& Kolstrup 2002).

Além disso, a chegada da "neotelevisão" (para usar o influente qualificativo cunhado por Eco (1986)) e os prognósticos mais temerários acerca do fim da "era da TV" (Gilder 1996; Pérez 2000) incitaram um crescente interesse arqueológico pelo meio em fase de mutação genética (ou de extinção). "Como la carta robada de Poe, no hay nada menos visible que lo que está a la vista", pondera Piscitelli (1995: 45). "Si ahora empezamos a ver a la televisión (algo muy distinto que ver televisión) es porque está empezando a desaparecer como un rostro de arena bañado por el mar".

As mudanças na estrutura da produção e do consumo televisivo (abundância de ofertas de canais; desarticulação na TV, da idéia de comunidade nacional; uso de controversas estratégias de sedução e fidelização da audiência; fragmentação do público em nichos de mercado baseados no gosto; hegemonia de novos gêneros e formatos, como os realitiy e os talk shows), fomentadas pelas novas tecnologias e pelo recente ambiente regulador, levaram pesquisadores europeus a interrogarem-se, por exemplo, sobre as circunstâncias históricas que permitiram a definição e implementação do serviço público de televisão, pondo em perspectiva suas eventuais e especificas virtudes políticas, culturais e estéticas (Branston 1998; Langc 2001).

\section{O processo de pesquisa: gravitando em torno de um objeto inapreensível?}

O primeiro e mais evidente obstáculo, na elaboração de uma história da televisão, é a busca e o processamento dos dados pertinentes, encontráveis em testemunhos orais, documentação escrita e registros audiovisuais (Alonso 2004; Bignell 2003: 36-40; Caughie 2000: 11-14; Comer 2003: 277-278; Jacobs 2000: 4-5, 8, 10-14; Lange 2001; Lagny 1998). O dificil acesso a este último de tipo de fonte representa sensivel desafio, em particular, para interessados na linguagem e nos padrões estéticos dos primórdios da TV. Enquanto os historiadores dispõem de contínuo (ainda que incompleto) acervo de obras do primeiro cinema, a televisão possui uma pré-história na qual os programas não eram gravados; para piorar, mesmo depois que o uso do vídeo-tape se tornou rotina, nos anos 60 , muito material foi desgravado para reutilização das fitas, deteriorou-se devido à incúria em sua conservação ou, simplesmente, foi descartado graças à falta de tino do seu valor histórico.

A ausência da garantia epistemológica do registro audiovisual é uma limitação para qualquer análise que procure apreender os estilos e as formas das primícias da TV, conforme admite Jacobs (2000: 4-5, 8, 10-14), em 
sua tentativa de reconstituição ou reconstrução de um sentido visual do antigo drama televisivo inglês (1936-1955). Pondera o autor, contudo, que a impossibilidade de contato com os programas em sua forma audiovisual original, embora imponha dificuldades significativas, não inviabiliza, fatalmente, a abordagem histórica de indole estética-formal, como prova a história do teatro, marcada por lacunas similares. Dada a inexistência de fontes primárias, cabe ao pesquisador reformular a noção de análise textual, recorrendo aos scripts e a todo "entorno discursivo" (Klinger 1997: 109) da produção em análise - resenhas, críticas, cartas de telespectadores, memorial de realizadores, memorandos internos da emissora, scripts, fotos e planos de gravação etc.

Escrever uma história da televisão não envolve, contudo, apenas a descoberta de documentos de antanho, mas também uma reflexão sobre como se engajar, de modo analítico e imaginativo, com aquele passado - isto é, com as conjunturas e os processos que assentam as condições de possibilidade não só para o funcionamento das instituições, como também para a construção dos discursos, dos imaginários, das representações e das práticas que circundam, interpretam e interpelam a indústria televisiva e seus produtos.

A elaboração e o desenvolvimento de uma pesquisa histórica comportam diferentes estágios que só posso recapitular, aqui, de modo bastante sucinto: a) formulação (e reformulação) de hipóteses estruturantes; b) a supracitada etapa de coleta e de organização disciplinada dos dados; c) assimilação dos fatos e eventos relevantes em quadros de referência coerentes: cronologia; periodização (o ordenamento cronológico da história em fases significativas, em consonância com desenvolvimentos no campo tecnológico, social, institucional ou estético); causalidade (individual, coletiva e estrutural); importância (influência, singularidade, tipicidade). A competência na interpretação da história (criação de estratégias inteligentes de leitura dos documentos escritos e dos registros audiovisuais, rechaçando o empirismo ingênuo) precisa estar aliada a certa engenhosidade narrativa; o somatório dos dois fatores deve resultar num texto final com timing para a suspensão do relato sintético das mudanças em benefício da pormenorização de acontecimentos especialmente densos e ressonantes (Bondebjerg 2002; Corner 2003).

Além de confrontar-se com exigências e desafios específicos, o historiador da televisão se depara com um problema familiar a todos os praticantes dos estudos televisivos: a definição do seu objeto. Referências ao caráter "complexo", "elusivo", "colossal", "caótico", "multifário", "híbrido", "desafiante" da TV como objeto de investigação critica e sociológica são de rigueur entre os analistas do meio (ver, por exemplo, Brunsdon 1998; Casetti \& Chio 1999: 13-15; Corner 2003: 275-276; Hartley 2000:34-36; Orozco Gómez 2001: 11-12). A natureza ambígua, polimorfa da televisão se reflete, obviamente, nos trabalhos de cunho histórico. Seguindo a trilha aventada 
por Corner (2003: 275-276), é possivel identificar, pelo menos, cinco aspectos diferentes da televisão, cada um dos quais candidatos a merecer atenção especial do historiador do meio:

1) A televisão como instituição, uma indústria c suas organizaçõcs, moldada pela política governamental c pela administração corporativa;

2) A televisão como realização, com foco na cultura c na prática profissional, cujo contexto histórico tende a ser delincado especialmente nos relatos autobiográficos;

3) A televisão como representação e forma, um cnquadramento estético que toma cmprestado o vocabulário da crítica litcrária, teatral c cincmatográfica;

4) A televisão como fenomeno sociocultural, profundamente interconcctado com a política, a esfera pública c a socicdade civil, com a cultura popular (e de massa), com o caráter mutável do lar c dos valores domésticos;

5) A televisão como tecnologia, um experimento cientifico que se tornou tanto um item doméstico como uma fonte crescentemente poderosa para uma mutaçào na cstética social.

Em que pese o potencial de detalhamento dos estudos focados somente em uma das dimensões acima, os trabalhos mais proficuos são aqueles que conseguem desvelar eixos de interconexão histórica entre vários aspectos do meio e de seu aparato, combinando pesquisa diligente com insights argutos. Não se trata de preconizar exatamente uma (a rigor, inexeqüível) "história total", nos moldes da sugerida por Klinger (1997), mas sim de salientar a importância de manter-se atento à multivascularidade do fenomeno televisivo, na hora de buscar causalidades e explanaçóes. Recentes estudos históricos da TV britânica cujo espirito condutor é a investigação formal constituem exemplos auspiciosos, nesse sentido, compatibilizando relatos detalhados de mudanças na técnica e na estética, no sistema genérico e no regime discursivo da fiç̧ão e do entretenimento televisivo com elucidações das estruturas institucionais, dos desenvolvimentos tecnológicos e do contexto sociocultural e artístico (Caughie, 2000; Corner 1991; Jacobs 2000). 


\section{Principais linhas de investigação na atualidade}

Enquanto que as parcas referências canônicas da história da televisão costumam trazer à cena, de forma supinamente panorâmica e linear, as grandes invenções, os personagens eminentes, as transmissões marcantes, os trabalhos mais instigantes publicados a partir da década de 1990 sobressaem por buscar abordagem mais focalizada e capaz de harmonizar a história social com indagações de orientação mais cultural.

Tais rupturas com o protocolo analítico tradicional estão afinadas com mudanças essenciais nos rumos da pesquisa historiográfica desde os anos 1960 , quando os historiadores se afastaram dos relatos mais convencionais a propósito de líderes e instituições políticas, e voltaram-se para as investigações da vida cotidiana de operários, criados, mulheres e outros grupos subalternos. Aqueles que se aproximaram da história cultural, na década de 1970, esperavam superar, por sua vez, as limitações normativas da perspectiva da história social, livrando-se de seu determinismo sociológico e de seus resultados estatísticos, ao mesmo tempo em que mantinham as portas abertas para as pessoas comuns que haviam sido convidadas à cena histórica pela geração anterior de pesquisadores. $O$ interesse cada vez maior pela história cultural (ou seja, pelo estudo das idéias, das atitudes, dos planos, das emoções, das representações ou dos artefatos por intermédio dos quais homens e mulheres de determinada época interagem com seu ambiente) permitiu explorar o passado de novas formas - ousar novos métodos, esmiuçar novas fontes (textos, imagens, ações) e indagar novas e mais sutis questões a respeito da vida cotidiana (Burke 1992, 2000; Chartier 1990; Darnton 1986; Fass 2003; Hunt 1992).

Ao constatar a fragilidade do método e do esquema interpretativo empregados, em regra, para abordar a história da televisão, os estudos mais recentes também passaram a enfatizar diferentes aspectos do passado, propondo novos assuntos e novas modalidades de investigação. Três áreas de pesquisa despontam, ao meu ver, como as mais promissoras:

1. Genealogia da televisão (Delavaud 2000, 2003; Uricchio 1992). A principal intenção, aqui, é construir uma arqueologia cultural da (nebulosa) pré-história da televisão - suas manifestações inaugurais, seus intrincados desenvolvimentos. São exumadas as primeiras utopias da televisão - a "televisão imaginada" (Delavaud 2000, 2003) -, a partir do levantamento e da análise de um conjunto variado de textos ficcionais, jornalísticos e científicos cuja preocupação comum é interrogar-se sobre as condições de emergência e de viabilidade do meio. Examina-se como a televisão foi antecipada, sonhada e projetada em diversos países: no período que precede imediatamente 0 aparecimento da instituição televisiva, em meados do século XX, mas, também, num período bastante anterior, quando progressos científicos e técnicos efetivados no século XIX (como a invenção do telefone e da experiência nova de simultaneidade a ele associada) pareciam autorizar a esperança de 
satisfação próxima do sonho da visão à distância, por meio da transmissão elétrica de imagens. As hipóteses e os argumentos visionários ou pragmáticos de escritores, jornalistas, cientistas, políticos e empresários foram antecedidos por um longo periodo de maturação da $\mathrm{TV}$, dentro do qual o meio emergente procurou reivindicar sua autonomia, distinguindo-se de outras mídias (telefone, cinema, rádio) com as quais mantinha interações recíprocas complexas. No atual estágio de convergência (de dispositivos e de interesses) das mídias, a investigação dos processos históricos de formação (e afirmação) da identidade da TV representa, sem dúvida, um subsídio valioso para as reflexões sobre o futuro do meio - sejam aquelas engendradas sob ótica tradicional sociológica ou socioeconômica, sejam as formuladas a partir de uma perspectiva semiótica centrada no novo conceito de intermediação.

2. Formação e desenvolvimento dos gêneros programáticos (Caughie 2000; Corner 1991; Forman 2003; Jacobs 2000). O mergulho no periodo formativo da televisão ambiciona, neste caso, esquadrinhar o processo histórico mediante o qual convenções genéricas foram concebidas e homologadas, enfocando o desenvolvimento das estratégias estéticas e discursivas e das práticas de produção de uma categoria de programa em particular. Tal qual assinalei antes, a meta é uma abordagem de caráter mais holístico que enfatize a complexidade das forças e das mediações sociais, culturais, econômicas e tecnológicas que envolvem o processo de formatação dos programas. A investida histórica na seara da apreciação qualitativa (técnica e estética) de gêneros ou programas típicos pressupõe (e oferece elementos para) uma revisão crítica da tendência de rejeição da análise textual profunda de programas individuais em favor de considerações mais abstratas sobre o "mysterium televisionis", sobre a "televisão em si mesma" que redundam, com freqüência, em repetitivas descriçōes da fenomenologia da televisão.

3. Arqueologia da recepção televisiva (Grimson et al 1999; Longo Elía 1999; Spigel 1992; Thumim 1995; Tichi 1991; Varela 1999). Como as pessoas experienciaram a chegada da TV em seu pais? Quais as condições, os locais e as rotinas de consumo televisivo? De que maneira estes padrões se relacionam com desigualdades de classe e com a divisão genérica do lazer e do trabalho doméstico? Em que medida o contexto social e cultural da recepção ajudou a moldar as práticas institucionais e textuais da televisão? Estas são algumas das indagações fundamentais que a arqueologia da recep̧̧ão televisiva tenciona responder, em sintonia com a nova historiografia do cinema e sua insatisfação com os relatos psicanalíticos abstratos, ahistóricos e universalizadores da relação texto/sujeito. Um dos marcos da área é a análise de Spigel (1992) a respeito de como as famílias brancas de classc mćdia aprenderam a conviver com a televisão como um objeto e um 
meio doméstico, nos Estados Unidos do pós-guerra. Dignos de notas são, também, neste campo, os trabalhos de Grimson et al (1999), Longo Elía (1999) e Varela (1999), que investigam a primeira década da TV na Argentina, realçando as estratégias adotadas para tornar a nova tecnologia familiar (nas diversas acepções do termo). Os vestígios da construção gradual do vínculo da audiência com a televisão são descobertos a partir da leitura da imprensa da época (jornais, revistas técnicas e culturais, de espetáculo e de atualidade) e da recuperação da memória (por intermédio de entrevistas abertas de tipo biográfico e de análise qualitativa de cartas) de pessoas que vivenciaram a pré-história do meio.

\section{A história da televisão no Brasil, uma vasta terra incognita}

As histórias da TV brasileira tendem a concentrar-se na dimensão institucional do meio, a exemplo do que ocorre com as pesquisas efetuadas em outros países latino-americanos (consultar, por exemplo, Orozco Gómez 2002). No caso específico brasileiro, a trajetória histórica da televisão é, em geral, delineada sob uma visada sociológica que prioriza - como parâmetro de análise e periodização - a influência (direta ou indireta; problemática; por vezes, espúria) do Poder (democrático/ ditatorial) e do Capital (nacional/ estrangeiro; em particular, estadunidense) na estruturação e no

208 desenvolvimento do serviço de TV e de suas organizações. Assim, o quadro de referência causal e explanatório ("Como surgiu a televisão? Quando, em que aspectos e por que mudou?") e crítico ("Quais as influências destas mudanças na vida social e política?”) é informado por questões ligadas à teoria da dependência; ao imperialismo e à homogeneização cultural; a projetos de governo desenvolvimentistas, nacionalistas ou neoliberais; ao processo de modernização autoritária; à difusão e ao reforço da ideologia dominante; à propaganda de produtos e de estilos de vida (Caparelli 1982; Caparelli \& Santos 2002; Jambeiro 2001; Mattos 1990, 2002; Oliveira 2001).

Sirva de exemplo, aqui, a exposição de motivos alinhavada por Mattos (2002: 15), na introdução de sua História da televisão brasileira:

Foram consideradas as decisões e implementação dè ações que acabaram por influenciar o desenvolvimento da nossa televisão. Em sintese, sob nosso ponto de vista, a história da TV brasileira reflete as fases do desenvolvimento e as políticas oficiais adotadas e por isso este veiculo não pode ser analisado como objeto independente do contexto no qual está inserido. 
O aludido "contexto" (quer dizer, as características da sociedade circundante que presumivelmente modelam o sistema televisivo) é reconstruído, por Mattos, com base em breve recapitulação da história do pais (ciclos econômicos; fatos politicos); em informações acerca de procedimentos governamentais de natureza estratégica, regulamentar ou censória, cujas fontes são artigos, decretos e capítulos constitucionais, pronunciamentos, declarações e reportagens publicadas na grande imprensa (amiúde, já citadas e interpretadas por outros autores); dados e quadros estatísticos socioeconômicos, demográficos, de análise quantitativa do conteúdo programático (1971), do número de televisores preto-e-branco e em cores em uso no país (1950-2001), da procedência dos equipamentos utilizados pelas emissoras de televisão (1971), entre outros do mesmo feitio.

A proposta do livro ("de caráter eminentemente descritivo e fundamentado no conhecimento existente" (16)) é, como indica o seu subtitulo, traçar "uma visão econômica, social e política" da história da televisão brasileira. Na prática, o que é efetivamente apresentado, ao leitor, é uma revisão cronológica das políticas governamentais de telecomunicação e do ordenamento jurídico da TV brasileira, conjugada com uma critica ideológica do impacto deste modelo televisivo (por intermédio dos programas, seu produto final) no incremento do consumo e na manutenção do status quo.

Não há espaço, aqui, para esmiuçar os equivocos das abordagens que tratam, de forma monolitica, os programas televisivos, admitindo a existência de um significado ideológico transparente e singular na superficie de sua representação, negligenciando as múltiplas camadas de comunicação, os diversos (e, às vezes, conflitantes) valores e ideais sociais registrados em toda produção cultural massiva. Restrinjo-me a assinalar desdobramentos indesejáveis deste pressuposto teórico, na pesquisa historiográfica. Embora seja importante contextualizar a indústria e os textos televisivos dentro de seu sistema de condicionamentos econômicos e políticos, é errado supor que a análise histórica do "contrato" ideológico e pecuniário forjado entre poderes de Estado, instituições políticas e organizações midiáticas ofereça explicação cabal para o desenvolvimento da forma e do conteúdo dos programas e, muito menos, para a codificação e decodificação do discurso televisivo.

Em virtude do caráter multifacetado (industrial, social, cultural e estético), a televisão é moldada tanto por fatores internos como por influências externas, abarcando um grande número de atores e instituições sociais na criação, na realização, na programação, na divulgação, na regulamentação, na crítica, no debate e no consumo de seu serviço e de seus produtos. Logo, qualquer estudo a propósito da formação e do desenvolvimento de uma cultura televisiva no país (cultura entendida, aqui, no sentido antropológico, como modo peculiar de viver e fazer a TV, a partir da imitação, apropriação, reinvenção de formas transnacionais), tem obrigação de contemplar, 
independente de qual seja o âmbito da pesquisa, outros elementos, além de notáveis agentes políticos e econômicos.

Quando decidi, cerca de cinco anos atrás, aventurar-me a estudar a TV sob uma perspectiva histórica, planejava documentar e analisar os encontros episódicos e as tentativas mais duradouras de interação dos literatos brasileiros com o moderno meio audiovisual (Freire 2002; 2003; 2004a). Julgava que as negociações e os conflitos que envolvem a presença efetiva e sui generis dos homens de letras dentro da indústria televisiva nacional permitiriam repensar a relação entre o intelectual, o popular e o massivo no país e, ao mesmo tempo, iluminar o desenvolvimento de nossa teledramaturgia - em especial, da telenovela, gênero fundamental sob o ponto de vista cultural e comercial. Não pretendia somente descrever o processo de adaptação dos escritores às exigências profissionais e ideológicas da nova forma de expressão cultural. A partir da análise qualitativa de biografias, cartas, crônicas, depoimentos e entrevistas (publicadas na imprensa ou reunidas em livros), almejava, também, caracterizar a formação, no seio da elite cultural, de representações e paradigmas críticos sobre a TV, enfatizando os tópos, as metáforas e os demais artifícios retóricos que informam este terreno discursivo complexo.

O contato mais estreito com as fontes primárias - vasculhadas na Biblioteca Nacional (RJ), na Fundação Casa Rui Barbosa (RJ), no Museu da Imagem do Som (RJ e SP) e nos arquivos do jornal O Globo e da extinta revista 210 Manchete (RJ) - foi evidenciando que a intelectualidade nativa nem sempre encarou a televisão como o inimigo público número um da literatura e do humanismo. Nas duas primeiras décadas de existência do veículo no Brasil, houve escritores e jornalistas culturais que, em contraste com as análises fatalistas de praxe, apostaram numa convivência mutuamente enriquecedora entre a galáxia de Gutenberg e a da imagem eletrônica, procurando assimilar as regras da linguagem televisiva, a fim de utilizá-las em prol da arte literária e da cultura livresca. Na busca de explanações comparativas, constatei que, ao longo dos anos 50 e 60 , membros das comunidades intelectual, literária e cinematográfica européia e estadunidense também levantaram, a seu modo, a bandeira da "televisão como a oitava arte" (Delavaud 2000b; Grasso 2002; Herms 2003; Lochard 2003; Rossellini 2001; Spigel 1998). Detectar similaridades e diferenças nas diversas tentativas de enlace crítico ou profissional com o novo meio se tornou, desde então, um dos aspectos centrais de minha abordagem.

A pesquisa sobre o período formativo da TV brasileira me proporcionou outras surpresas. Devido ao fato de, entre 1950 e 1964, o televisor ser um bem de consumo circunscrito aos endinheirados, idealiza-se o perfil "cultural" (na acepção ilustrada do termo) da programação do período, classificado de "elitista" pelos historiadores. Teleteatros, óperas e balés não lastreavam, sozinhos, a televisão da "era dourada"; pululavam no vídeo 
atrações mais afinadas com a tradição lúdico-festiva dos entretenimentos populares - circo; folhetim; imprensa sensacionalista; melodrama; jogos; teatro de revista (Freire Filho 2003; 2004b).

É dificil escapar dos enquadramentos emocionais e afetivos, quando contemplamos o passado - os historiadores da televisão, por exemplo, se mostram inclinados a manter relação sentimental com certos períodos ou programas antigos; mais raramente, manifestam um senso exacerbado de distanciamento, a partir do qual o passado é avaliado, com base em critérios atuais, como limitado ou anedótico (no plano social, tecnológico ou estético) ou mesmo indigno de ser estudado (Corner 2003: 274). No caso da historiografia praticada no Brasil, a razão principal da vișão romantizada dos primórdios da TV é a assimilação acrítica dos relatos autobiográficos dos "pioneiros" (Barbosa Lima, 1991, Barbosa Lima \& Clark 1988; Loredo 2000; Silva Júnior 2001), submetidos ao trabalho de inflexão, seleção ou transmutação da memória (Girardet 1987; Ong 1983).

Concorre, ainda, para o juizo enganoso acerca do "alto nível cultural da programação", a teima em confundir capital econômico e capital cultural, na hora de inferir o gosto da audiência. Para entender a heterogeneidade das atrações levadas ao ar, já na "fase elitista", não basta, porém, relativizar o gosto dos afortunados proprietários de televisor, que não desperdiçavam a chance de pavonear seu novo símbolo de status - "Hoje, na Paulicéia, entre os elegantes da sociedade, existe uma nova fórmula de convite, para os encontros da tarde: Célia Maria telefona a Maria da Glória dizendo: - Venha tomar chá comigo e assistir à televisão" (O Cruzeiro, 28/10/1950: 37-38). É preciso considerar, também, o interesse precoce das emissoras em seduzir um contingente populacional que se familiarizava com a TV por intermédio de seu consumo em espaços públicos:

Na capital paulista, hoje, pode-se assisti; de qualquer ponto da cidade, aos programas normais da televisão que a PRF-3TV manda para o ar diariamente das $17 \mathrm{~h}$ às $19 \mathrm{~h}$ Centenas de aparelhos receptores foram instalados nas vitrines dos grandes estabelecimentos comerciais, e nas prateleiras dos bares, cafés e confeitarias. Diante desses receptores, há uma multidão de espectadores acompanhando "shows" que se desenrolam nos estidios da TV no Sumaré, ou então assistindo (sic) os "shorts", desenhos animados, atualidades, transmitidos em filmes como no cinema (idem, ibidem).

Hipérboles à parte, encontramos informações similares acerca da penetração amplificada da TV (mediante a exibição fora da esfera privada), em 
fontes menos suspeitas do que $O$ Cruzeiro (parte do conglomerado midiático capitaneado por Assis Chateaubriand). À medida que me conscientizava da vitalidade das discussões públicas sobre a nova tecnologia, fui chegando à conclusão de que minha versão dos debates históricos acerca do valor cultural da televisão - ainda que continuasse prioritariamente focada nas ações, nos julgamentos normativos e nas perspectivas ideológicas da comunidade artística e intelectual - deveria refletir, também, o pensamento e as práticas dos donos e do staff das emissoras, de governantes e legisladores e das audiências, destacando divergências e alianças provisórias nos esforços para definir o significado e mediar ou conter a ascendência do moderno dispositivo audiovisual no Brasil.

Baseado nesta premissa, alarguei consideravelmente o escopo da pesquisa e o perímetro das fontes primárias, arregimentando notícias, reportagens, editoriais, artigos, crônicas, fotos, charges e anúncios veiculados na imprensa feminina e em publicações especializadas na indústria da diversão (rádio e cinema, sobretudo). A versão final do projeto (intitulada Os intelectuais, as massas e a TV no Brasil: história cultural de um relacionamento complexo) ambiciona contemplar, portanto, o debate intelectual e popular acerca das funções e dos efeitos sociais e culturais da televisão (diversão/ saber; declínio/incentivo da leitura; rebaixamento/elevação da qualidade das expressões culturais concorrentes; fortalecimento/erosão dos laços domésticos e da identidade nacional; alienação/conscientização das massas 212 etc) - desde a chegada do veículo, ao país, como mera curiosidade técnica até sua consolidação como instituição, indústria, linguagem e forma hegemônica de entretenimento.

Embora se concentre nas décadas de 1950 a 1980, minha pesquisa recua, de forma estratégica, até os anos 30 , quando foram realizadas as primeiras experiências e demonstrações com a nova tecnologia da TV, em território nacional (arrefecidas, na década 40, não apenas no Brasil, mas em todo o mundo, em função da Segunda Guerra). Dou destaque, especialmente, à $1^{a}$ Exposição de Televisão, instalada, em 1939, no pavilhão de entrada da Feira de Amostras do Rio de Janeiro. No dia de 03 de junho, o presidente Getúlio Vargas inaugurou o evento, organizado pelo Ministério dos Correios da Alemanha, com patrocínio do Departamento Nacional de Propaganda. Compareceram, ao recinto abarrotado da exposição, jornalistas, figuras de proa da política, membros da alta sociedade e insignes representantes da comunidade científica nativa. Movidos por interesses políticos e econômicos, também estiveram, por lá, engenheiros e autoridades germânicas, como Hans Pressler, conselheiro do Instituto de Pesquisa dos Correios do Terceiro Reich, e Von Lebetzow, encarregado de negócios da Alemanha no Rio de Janeiro.

Coube ao Dr. Arthur Hehl Neiva, destacado junto à missão germânica, detalhada apresentação oral do processo científico da TV. Logo depois, iniciou-se o aguardado espetáculo da "visão à distância". Receptores da marca Telefunken 
transmitiram, para centenas de curiosos, não apenas a voz, mas também fisionomias e gestos de celebridades do rádio carioca, que se apresentavam num estúdio montado em outro extremo do pavilhão da Feira. Francisco Alves, o Trio Dalva de Oliveira e as Irmãs Pagãs (que interpretaram um samba, acompanhadas pelo conjunto regional de Benedito Lacerda) tiveram a honra de ser os primeiros artistas televisionados.

A atração seguinte foi o visiofone - conjugação de aparelho telefônico e de televisão, que permitia aos interlocutores conversar e trocar olhares simultaneamente. Getúlio e o ministro da Justiça Francisco Campos experimentaram, risonhos, a invenção. A fim de demonstrar todas as possibilidades da TV, a inauguração oficial foi encerrada com transmissão de um discurso do presidente, filmado pelo DNP, em dezembro de 1938, durante a Exposição do Estado Novo.

No dia 04 de junho de 1939, a Exposição de Televisão foi aberta ao público, assim permanecendo, com sucesso, por quinze dias. A imprensa deu ampla cobertura a todo o evento - posteriormente ignorado pela maioria dos historiadores (Federico 1982; Sampaio 1984; Vampré 1979), não obstante sua poderosa dimensão simbólica. Jornais e revistas saudaram, em regra, a chegada da "extraordinária invenção", do "prodígio moderno", da "maravilha do século", do "mais genial processo de comunicaçōes até hoje inventado pelo gênio humano" - a televisão, "em toda a sua impressionante realidade". A despeito do preço elevado (mais o menos o dobro do custo de um aparelho de rádio), observadores da época previam que a TV estava destinada a reformar, dentro de pouco, todo o andamento do "broadcasting", não tardando a incorporar-se "aos gozos triviais da existência".'

Todavia, pareceres menos favoráveis também emanavam dos periódicos. Artigo assinado por J. Seabra, na revista Careta, advertiu que o governo estava prestes a realizar um péssimo negócio, "levando gato por" lebre" - "A geringonça que se instalou na Feira de Amostras e que vinham chamando televisão está muito longe de ser o que circula com designação igual nos paises mais adiantados e mais felizes do que o nosso"; "a aparelhagem caduca que pretendem vender como coisa nova a um de nossos ministérios é uma caricatura grotesca e monumental"; "coisa obsoleta e que não convence" (48). No Jornal das Moças, o colunista Paulo Roberto manifestou inquietação, por sua vez, quanto a duas das possiveis alterações determinadas pela "revolucionária aparelhagem da nova técnica do rádio": De que viverá o futebol, caso possamos assistir aos jogos em casa? E a indústria cinematográfica, como vai sobreviver, se pudermos desfrutar de filmes, na comodidade de um pijama? O autor logo tratou de tranqüilizar suas leitoras: os "encarregados de equilibrar a complicada balança da vida social" que pensassem nos problemas ocasionados pelo advento da visão à distância - "Nós, que nada temos com estes altos assuntos, nem ganhamos 
para resolvê-los, podemos ficar serenamente pensando, só e sempre, na maravilhosa inovação que a ciência nos trouxe em boa hora" (15/06/ 1939: 22).

É desnecessário frisar a atualidade política, econômica, social e cultural das questões levantadas naqueles longínquos anos 30 - período em que a transmissão a partir de uma unidade central para o consumo privado e doméstico ainda não havia sido naturalizada. Como argumenta Caughie (2000: 13), a pesquisa histórica sobre a televisão nos oferece um registro das diferenças do passado que serve para lembrarnos o que presente pode ser - ou poderia ter sido. As possibilidades alternativas ou experimentais de uso interativo e de recepção pública sumariadas acima ratificam que a definição da TV como meio centralizado de comunicação de massa - experienciada e conceituada como axiomática, genética, universal - foi determinada historicamente por estruturas socioeconômicas e pelos modos de vida dominantes nas sociedades modemas ou em fase de modernização (Allen 1983; Gripsrud 1998), estando, portanto, aberta a mudanças.

Presumo que o exame (altamente seletivo, claro) de expectativas e temores veiculados durante a Exposição de Televisão ilustrou, um pouco melhor, o tipo de abordagem de minha pesquisa - centralizada na busca de representações e paradigmas interpretativos sobre a televisão já esquecidos ou ainda proeminentes no debate público. Como acontece (de maneira menos ou mais consciente) em toda investigação histórica, minha apreciação das polêmicas envolvendo a função social, as formas de propriedade e controle, as 214 potencialidades expressivas e o valor cultural da televisão está condicionada por inquietações pessoais e problemas hodiernos. Espero, mais concretamente, que do meu relato da intricada sedimentação de uma cultura televisiva no país (modos específicos de ver e julgar) possam ser extraídas lições proveitosas para o enriquecimento da agenda crítica dos (tão em voga) debates sobre a qualidade da TV - perigosamente ameaçados por teorização precária, superficialidade analítica e amnésia histórica (Freire 2001; 2004a).

\section{Bibliografia}

AGGER, Gunhild. Proximity and distance: perspectives for analysis of TV fiction and its history. In: BRÜGGER, Niels \& KOLSTRUP, Soren (ed.), Media history: Theories, methods, analysis, p. 149-174. Aarhus: Aarhus University Press, 2002.

ALLEN, Jeanne (1983). The social matrix of television: invention in the United States. In: KAPLAN, Ann (ed.), Regarding television: critical approaches an anthology, p. 109-119. Frederick, MD: University Publications of America. 
ALONSO, Rafael Gómez. Investigar la historia de la televisión en España: algunos problemas documentales y metodológicos. Www.ucm.es/info/cavpl/ Area\% 20Abierta $7 \%$ 20Areat\%20Abierta/ articulos/RafaEdit.pdf. 2004.

ANDERSON, Christopher \& CURTIN, Michael. Writing cultural history: the challenge of radio and television. In: BRÜGGER, Niels \& KOLSTRUP, Soren (ed.), Media history: Theories, methods, analysis, p. 15-32. Aarhus: Aarhus University Press, 2002.

BARBOSA LIMA, Fernando. 40 anos da televisão latino-americana. Comunicação \& Política, nº 13-14, p. 99-112, 1991.

BARBOSA LIMA, Fernando \& CLARK, Walter. Um pouco de história e de reflexão sobre a televisão brasileira. In: MACEDO, Cláudia \& FALCÃO, Ângela (orgs.), TV ao vivo: depoimentos. São Paulo: Brasiliense, 1988.

BIGNELL, Jonathan. An introduction to television studies. London: Routledge, 2003.

BODDY, William. Fifties television: the industry and its critics. Chicago: University of Illinois Press, 1990.

BONDEBJERG, Ib. Scandinavian media histories. A comparative study: Institutions, genres and culture in a national and global perspective. Nordicom Review, vol. 23, $\mathrm{n}^{\mathrm{O}}$ 1-2, p. 61-79, 2002.

BOURDON, Jérôme. L'archaïque et la postmoderne: éléments pour l'histoire d'un peu de télévision. In: BOURDON, Jérôme \& JOST, François (ed.), Penser la télévision, p.10-20. Paris : Nathan, 1998.

BRANSTON, Gill. Histories of British television. In: GERAGHTY, Christine \& LUSTED, David (eds.), The television studies book, p. 51-62. London \& New York: Arnold, 1998.

BRIGGS, Asa \& BURKE, Peter. Uma história social da midia: de Gutemberg à Internet. Rio de Janeiro: Jorge Zahar, 2004.

BRUNSDON, Charlotte. What is the "television" of television studies? In: GERAGHTY, Christine \& LUSTED, David (eds.), The television studies book, p. 95-113. London: Arnold, 1998.

BURKE, Peter. Abertura: a nova história, seu passado e seu futuro. In: BURKE, Peter (org.). A escrita da história: novas perspectivas. São Paulo. Ed. UNESP, 1992. Brasileira, 2000.

Variedades de história cultural. Rio de Janeiro: Civilização

CAPARELLl, Sérgio. Televisão e capitalismo no Brasil. Porto Alegre: L\&PM, 1982. CASETTI, Francesco \& CHIO, Federico di. Análisis de la televisión instrumentos, métodos y prácticas de investigación. Barcelona: Paidós, 1999. CAUGHIE, John. Television drama: realism, modernism and British culture. Oxford: Oxford University Press, 2000.

CHARTIER, Roger. A história cultural: entre práticas e representações. Lisboa. Difel, 1990.

CORNER, John (ed.). Popular television in Britain: essays in cultural history. London: British Film Institute, 1991. 
. Critical ideas in television studies. Oxford: Clarendon Press,

Finding data, reading patterns, telling stories: issues in the historiography of television. Media, Culture \& Society, vol. 25, n ${ }^{\circ} 2$, p. $273-$ 280, 2003.

CORRIGAN, Philip. The 'moment' of English television 1936-1939. In: SYVERTSEN, Trine (ed.), 1992 and after: Nordic television in transition, $p$. 130-160. Bergen: University of Bergen, 1990.

DARNTON, Robert. O grande massacre de gatos, e outros episódios da história cultural francesa. Rio de Janeiro: Graal, 1986.

DELAVAUD, Gilles. (ed.). Un siècle de télévision. Anticipation, utopie, prospective. Dossiers de l'audiovisuel, $\mathrm{n}^{\circ} 112$, novembre-décembre, INA, 2003.

- La télévision avant la télévision. In: DARRAS, Bernard \& THONON, Marie (ed.), Médias 1900-2000, p. 97-114. Paris : L'Harmattan, $2000 \mathrm{a}$.

André Bazin, critique de télévision. Trabalho apresentado no VI

Rencontres INA-Sorbonne. http://www ina.fr/inatheque/activites/sorbonne/ index.fi:html. 2000b.

ECO, Umberto. TV: la transparencia perdida. In: La estrategia de la ilusión, p. 200-223. Barcelona: Lumen, 1986.

FASS, Paula S.. Cultural history/social history: some reflections on a continuing dialogue - the cultural turn and beyond. Journal of Social History, vol. 37, $\mathrm{n}^{\circ}$ 1, p. 39-47, 2003.

FEDERICO, Maria Elvira Bonavita. História da comunicação - rádio e TV no Brasil. Petrópolis, RJ: Vozes, 1982.

FREIRE FILHO, João. TV de qualidade: uma contradição em termos? Libero, ano IV, vol. 4, $\mathrm{n}^{\circ} 7-8$, p. 86-95, 2001.

. A "esfinge do século": expectativas e temores de nossos homens de letras diante do surgimento e da expansão da TV. Alea: Estudos Neolatinos, vol. 4, n 2, p. 243-264, 2002.

1,p.105-124, 2003.

. A TV, os literatos e as massas no Brasil. Contracampo, vol. $8, \mathrm{n}^{\circ}$

. Decifrando os mistérios da "oitava arte": A crítica televisiva no

Jornal de Letras (1950-1970). Trabalho apresentado no XIII Encontro Anual da COMPÓS, realizado na Universidade Metodista de São Paulo (São Bernardo do Campo/SP), de 22 a 25 de junho de 2004.

GILDER, George. A vida após a televisão. Rio de Janeiro. Ediouro, 1996.

GRASSO, Aldo (org.). Schermi d'autore. Intelletuali e televisione (19541974). Roma: RAI, 2002.

GRIMSON, Alejandro et al. Un electrodoméstico en la ciudad. Hacia una conceptualización del lugar de la televisión en el espacio público. 
In: GRIMSON, Alejandro \& VARELA, Mirta, Audiencias, cultura y poder, p. 197-225. Buenos Aires: Eudeba, 1999.

GUMBRECHT, Hans Ulrich. "Sua janela para o mundo" ou como da mídia "televisão" surgiu a "realidade televisiva". In: Modernização dos sentidos, p. 261-274. São Paulo: Editora 34, 1998.

HERMS, Josep M. Baget. Televisió de qualitat: evolució històrica del concepte. http://www aludiovisualcat.net/publicacions/l3.pdl. 2003.

HUNT, Lynn (ed.). A nova história cultural. São Paulo: Martins Fontes, 1992. JACOBS, Jason. The intimate screen: early British television drama. Oxford: Oxford University Press, 2000.

JAMBEIRO, Othon (2001). A TV no Brasil do Século XX. Salvador: EDUFBA. KLAGSBRUNN, Marta \& RESENDE, Beatriz (org.). Quase catálogo - A telenovela no Rio de Janeiro (1950-1963). Rio de Janeiro: CIEC/ECO-UFRJ/ Secretaria de Estado de Cultura, 1991.

KLINGER, Barbara. Film history terminable and interminable: recovering the past in reception studies. Screen, vol. 38, n² 2, p. 107-128, 1997.

LAGNY, Michèle. L'accès aux sources télévisuelles. In : BOURDON, Jérôme \& JOST, François (ed.), Penser la télévision, p. 44-52. Paris : Nathan, 1998. LANGE, André. Introduction à l'histoire de la télévision. hup://hisiv2. frue fr/. 2001. LOREDO, João. Era uma vez... a televisão. São Paulo: Alegro, 2000.

LONGO, Fernanda Elía. Cartas a la televisión: memoria, biografia e identidad cultural. In: GRIMSON, Alejandro \& VARELA, Mirta, Audiencias, culturay poder-estudios sobre la televisión., p. 177-195. Buenos Aires: Eudeba, 1999. MATTOS, Sérgio. Um perfil da TV brasileira. Salvador: A Tarde, 1990.

. História da televisão brasileira - uma visão econômica, social e política. Petrópolis, RJ: Vozes, 2002.

OLIVEIRA, Lúcia Maciel Barbosa de. "Nossos comerciais, por favor!": a televisão brasileira e a Escola Superior de Guerra. São Paulo: Beca, 2001. OROZCO GÓMEZ, Guillermo (ed.). Historias de la televisión en América Latina. Barcelona: Gedisa, 2002.

OROZCO GÓMEZ, Guillermo. Televisión, audiencias y educación. Bogotá: Norma, 2001.

PÉREZ DE SILVA, Javier: La televisión ha muerto. Gedisa: Barcelona, 2000.

PISCITELLI, Alejandro. De la centralización a los multimedios interactivos. Diálogos de la Comunicación, no 41, marzo, p. 21-35, 1995.

ROSSELLINI, Roberto La télévision comme utopie. Paris: Cahiers du cinema, 2001. SAMPAIO, Mario Ferraz. História do rádio e da televisão no Brasil e no mundo - memórias de um pioneiro. Rio de Janeiro: Achiamé, 1984.

SMITH, Anthony \& PATERSON, Richard (eds.). Television: an international history. Oxford: Oxford University Press, 1998.

SPIEGEL, Lynn. Make room for $T V$ : television and the family ideal in postwar America. Chicago: Chicago University Press, 1992. 
The making of a TV literate elite. In: GERAGHTY, Christine \& LUSTED, David (eds.), The television studies book, p.63-85. London \& New York: Arnold, 1998.

SILVA JÚNIOR, Gonçalo. Pais da TV - a história da televisão brasileira contada por - São Paulo: Conrad Editora do Brasil, 2001.

THUMIN, Janet. "A live commercial for icing sugar". Researching the historical audience: gender and broadcast television in the 1950s. Screen, vol. $38, \mathrm{n}^{\circ} 1$, p. 48-55, 1998.

Tauris, 2002.

(ed.). Small screen, big ideas: television in the 1950s. London: I.B.

URICCHIO, William. Television as history: representations of German television broadcasting, 1935-1944. In: MURRAY, Bruce \& WICKHAM, Christopher (eds.), Framing the past: the historiography of German cinema and television, p. 167196. Carbondale: Southern Illinois University Press, 1992.

\section{Notas}

'Informações e comentários extraídos de Gazeta de Notícias, 02/06/1939: 9; idem, 04/06/1939: 1, 20; Jornal do Comércio, 03/06/1939: 7; idem, 04/06/1939: 9; Jornal do Brasil, 03/06/1939: 13; idem, 04/06/1939: 7; Correio da Manhã, 04/06/1939: 4; O 218 Jornal, 04/06/1939: 7; Revista da Semana, 10/06/1939: 24; Revista Carioca, 10/06/ 1939: 34-35; Diário de Notícias, 15/06/1939: 4; Jornal das Moças, 15/06/1939: 22; Cine-Rádio-Jornal, 15/06/1939: 3; Careta, 08/07/1939: 38 e 43.

\section{Palavras-chave}

1. Televisão

2. Estudos televisivos

3. História da televisão

4. Teoria

5. Metodologia 